\title{
CUERPO INDETERMINADO: LA PRECARIEDAD DEL CUERPO EN EL DISCURSO FEMINISTA
}

\author{
María Isabel Peña Aguado
}

\section{Resumen/Abstract}

La teoría feminista heredó de una tradición filosófica hostil la identificación de cuerpo y mujer. Partiendo de esa identificación entre mujer y cuerpo es comprensible que un cuestionamiento del concepto 'mujer' influya asimismo en el lugar que va a encontrar el cuerpo dentro del movimiento y teoría feministas. Ese lugar será diferente dependiendo de las diversas reivindicaciones que marcan las diferencias entre los distintos feminismos y teorías queer. La pregunta que se plantea es hasta qué punto la precariedad del cuerpo femenino dentro de la misma teoría feminista es consecuencia del cuestionamiento del concepto de mujer o si, por el contrario, no será más bien el rechazo a una realidad corporal concreta lo que ha permitido y ayudado a desarmar los conceptos de 'mujer' y 'mujeres' hasta el punto de considerarlos como innecesarios para el mismo discurso y políticas feministas contemporáneos.

Palabras claves: cuerpo, mujeres, feminismo, teoría queer.

INDETERMINACY OF THE BODY: PRECARIOUSNESS OF BODY IN THE FEMINIST DISCOURSE

Feminist theory inherited the identification of woman and body from a hostile philosophical tradition. Given this identification, it is understandable that a questioning of the concept, woman' also influences the place that the body will find in the feminist movements and theories. The question that arises is how far the precariousness of the female body within feminist theory itself is the result of a questioning of the concept of 'woman' or whether, on the contrary, it is the

1 Española, Instituto de Humanidades de la Universidad Diego Portales. Email: maria.pena@udp.cl 
rejection of a concrete corporal reality which has enabled and helped to disarm the concepts of, woman' and,women' to the point of considering them unnecessary for contemporary feminist discourse and politics.

Keywords: body, women, feminism, Queer Theory.

\section{A modo de preámbulo}

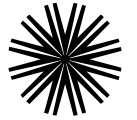

Tal vez ya el título de este texto despierte susceptibilidades en aquellos lectores y lectoras duchos en materia feminista, pues me sitúa -según qué miradas y lecturas- en un lugar del espacio y del tiempo feminista ya pasado de moda. Un feminismo que se ha definido últimamente como "gris, normativo y puritano" y al que se le ha acusado de ser de marcado carácter heterosexual y eurocentrista ${ }^{2}$. Un feminismo que todavía estaría anclado en cierto universalismo desde el que se atrevería a hablar de el cuerpo y el feminismo (el discurso feminista) sin tener en cuenta la pluralidad de miras y argumentos que recorren los distintos planteamientos feministas, ni los nuevos espacios de visibilidad que se han abierto, ni tampoco los cuerpos que se mueven y habitan en ellos.

Cierto es que nuestro tiempo ya hace mucho que dejó de ser uno de singularidades determinadas y generalizantes a la vez $-e l$ feminismo, el cuerpo-, para convertirse en el de las pluralidades que protestan ante cualquier aproximación o regulación que no sea igualmente plural. Así, la teoría feminista no es una excepción en reivindicar un talante plural que por otra parte la ha caracterizado desde el principio tanto en los asuntos que planteaba como en las distintas perspectivas desde las que se abordaban esos temas, dando lugar a la diversidad de los discursos y sujetos que han fluido y confluido a configurar espacios y voces feministas.

No voy iniciar una reflexión extensa de si hay o no una historia del feminismo o si los distintos feminismos tienen cada uno su historia, pero sí quiero dejar constancia de que más que de escribir una historia en el sentido

2 “... que ve en las diferencias culturales, sexuales o políticas amenazas a su ideal heterosexual y eurocéntrico de mujer” (Preciado, 2008: 236). 
de cambio o de progreso se trataría de atender a los diferentes contextos (Linda Nicholson, 2008: 140) en los que van surgiendo las miradas feministas que conviven, si no en armonía, al menos sí en sincronía ${ }^{3}$. Esta sincronía suspende el tiempo para abrir espacios. El cómo algunas formas del feminismo van ganando protagonismo y el porqué unos discursos abren más perspectivas que otros -dándoles más fuerza y haciéndolos aparecer como el feminismo más actual- es algo que solo puede explicarse atendiendo a la superposiciones así como a los cruces entre el discurrir de las diferentes voces. Para entender los encuentros y desencuentros dentro del feminismo actual, podría servir aquella descripción que hacía Foucault de su "época actual" -y esa actualidad se refería a finales de los ańos sesenta del siglo pasadocomo una "época del espacio" como una "época de lo simultáneo", de la "yuxtaposición” y, por ende, "de lo disperso" (Foucault, 2010: 63). Quizá los debates feministas estén motivados no tanto por las distintas visiones y las desavenencias entre aquellos (as) "piadosos (as) descendientes del tiempo" y los(as) "habitantes encarnizados (as) del espacio" (Foucault, 2010: 64), sino por las que han surgido en el seno mismo de estos últimos. Y subrayo el adjetivo 'encarnizado' porque en él está contenida una fuerte reminiscencia de la carne, materia también del cuerpo, que sirve de inspiración, en parte, a estas reflexiones sobre el cuerpo y su lugar en los espacios feministas actuales. Y expresa -también en parte- el marco referencial desde el que quiero abordar el tema del cuerpo, pues no cabe duda de que buena parte del espacio feminista actual está poblado por cuerpos entregados a litigios sin solución ${ }^{4}$.

Mi interés por el concepto de cuerpo que se maneja en las teorías feministas así como por el lugar que ocupa y ha ocupado dentro de ellas surge desde la necesidad de entender si tiene sentido hoy en día hablar de feminismo. Y si es así, comprender desde dónde y a quién le habla el feminismo contemporáneo. Tanto mi interés como el marco elegido se justifican por el creciente protagonismo que el cuerpo -debería decir más bien los cuerpos-

3 "I believe, however, that I would be a mistake to subscribe to a progressive notion of history in which various frameworks are understood to succeed and supplant one another. There is no story to be told about how one moves from feminist to queer to trans. The reason there is no story to be told is that none of these stories are the past; these stories are continuing to happen in simultaneous and overlapping ways as we tell them. They happen, in part, through the complex ways they are taken up by each of these movements and theoretical practices" (Butler, 2004: 4).

4 Más que de un litigio se trataría de una "diferencia" (diferendo) en el sentido que usa el término Jean François Lyotard (Lyotard, 1988: 9). 
han tomado en el discurso del feminismo actual. A esto se suma que son esos nuevos cuerpos los que se han convertido en el espacio político desde el que alza la voz y actúa el feminismo hoy en día. Las controversias en la teoría feminista ya no se dan alrededor de la reivindicación de derechos, ni tampoco se plantean como una revolución de los espacios privados o públicos, sino que se sitúan en cuerpos cuya legitimidad o marginalidad se discute. Son esos cuerpos los que han puesto en jaque a las mujeres como sujeto del feminismo contemporáneo5.

Visto así, podría preguntarse qué sentido tiene hablar de la precariedad del cuerpo dentro del discurso feminista. Una primera respuesta nos remite al llamado feminismo de la "segunda ola", denominación que sirve para señalar aquel momento histórico que comenzó en los años sesenta del siglo pasado, crucial no solo para el feminismo como movimiento político sino también para la teoría feminista que se va a desarrollar a lo largo de los años setenta. Es justamente en ese tiempo cuando las llamadas "políticas de identidad" (Nicholson, 2008) agrupadas alrededor de las diferencias cuestionan de un modo radical las categorías mujer y mujeres, y si bien las diferencias e identidades que se perfilan tienen matices 'corporales' (las reivindicaciones de las mujeres negras, por ejemplo), la insistencia en el contenido social de la discriminación sexual provoca o bien olvido o bien rechazo del cuerpo, más biológico o de lo más biológico del cuerpo, si se prefiere. A esta lectura se podrá alegar que este tiempo también coincide con el momento en el que las mujeres, en el contexto de la lucha por la despenalización del aborto, reivindican su vientre como propio, lo que daría pie a pensar que más que un rechazo al cuerpo, se estaría tomando una conciencia desde el mismo. A eso cabría responder que estas reivindicaciones, más que significar una revaloración del cuerpo femenino por parte de las feministas, indicaban hasta qué punto el cuerpo femenino aparecía como obstáculo para la realización de la igualdad. En una segunda instancia, se podría responder llamando la atención sobre la precariedad de los cuerpos que desde los márgenes se han movido al centro del feminismo. Los márgenes a los que me refiero aquí, especialmente los de la teorías queer, no son ya tales, y la precariedad de esos cuerpos tiene otra dimensión que la del rechazo que he atribuido a las teorías de la segunda ola. Más que de rechazo se trataría en realidad de una sobreacentuación y sobreexposición de corporalidades. Dicho con otras palabras: mi hipótesis es que durante un tiempo el feminismo, huyendo de un biologismo discriminatorio, se empeñó

5 Cf. Peña 2015. 
en olvidar un cuerpo que, puesto en los márgenes, vuelve ahora envuelto en un lenguaje renovado e irreverente; tras el que, empero, se esconde más sexualidad y biología (aunque sea biotecnología) de la que el feminismo en otro tiempo se atrevió a enfrentar.

Es este viaje de ida y vuelta el que podría contribuir a perfilar la precariedad así como la indeterminación del cuerpo en el marco del feminismo y al mismo tiempo a contextualizar su papel dentro de los debates feministas.

\section{Cuerpo indeterminado}

La tradición filosófica ha identificado cuerpo y mujer. Excluidos ambos de una racionalidad que guarda distancia de todo lo sensible a la vez que intenta mantenerlo bajo control, los dos conceptos se confunden en el discurso. No sorprende pues que Terry Eagleton en su libro The Ideology of Aesthetic afirme que la estética nace como un discurso sobre el cuerpo y también como "mujer" (Eagleton, 1990: 13, 16). Igualmente, la socióloga suiza Claudia Honegger en su libro Die Ordnung der Geschlechter. Die Wissenschaften vom Menschen und das Weib 1750-1850. (El orden de los géneros. Las ciencias humanas y la hembra 1750-1850) nos recuerda que, mientras la ilustración coloca al hombre en el centro de las humanidades, la mujer encuentra su lugar como objeto de estudio en la ginecología, una ciencia que no es nueva, pero desde la que el siglo XVIII 'explica' a la mujer en un cruce de discursos filosóficos, psicológicos y sociológicos que sirven para justificar 'científicamente' el orden de géneros establecido.

En este orden binario, la identificación de mujer y cuerpo supone, casi como si fuera una ecuación, que los dos conceptos se van a convertir en intercambiables. Claro que no se trata de el cuerpo. No se trata del cuerpo que se puede rastrear en la historia de la filosofía desde sus comienzos. Mucho menos de aquella res extensa cartesiana que de un modo casi geométrico se opone al cogito. Tampoco de ese cuerpo por el que conocemos el mundo y nos relacionamos con él y que a menudo nos lleva al engaño y a confundir la realidad. No se trata, por último, del cuerpo humano, ese cuerpo neutral, de carácter universal, que da la pauta de todos los cuerpos, sin sexo, por supuesto, y susceptible de ser descrito desde la ciencia, la biología y la fisiología entendidas todas ellas de un modo igualmente objetivo, neutral y universalmente válido como el cuerpo al que describen (Sarasin, 2011: 13). Ni siquiera de un cuerpo hecho deseo y movido por fuerzas libidinales. 
El cuerpo que se asocia con la mujer es un cuerpo encarnado y abierto, atravesado de fluidos y olores que hay que mantener limpio y domesticado. Es un cuerpo inmanejable ya sea por su debilidad o, por el contrario, a causa de la fuerza que se oculta dentro, pues puede acoger a otro cuerpo dentro de sí, e incluso alimentarlo después. Es un cuerpo impuro, es carne y sangre que se desboca y desordena, que se ríe de la ley, como aquellas mujeres de El arte de la guerra de Sun Tzu que finalmente son decapitadas; pierden la cabeza. Una cabeza que, como nos recuerda Hélène Cixous, pierden de todos modos, pues o se les corta o se les roba provocando su silencio y obediencia.

Es el cuerpo femenino el que indetermina el cuerpo y lo convierte en un cuerpo. Es el cuerpo femenino el que marca la diferencia que finalmente se va a leer como deficiencia (Schmid, 1995: 55-79). Pero es también ese cuerpo el que ejemplifica hasta qué punto un cuerpo se vive, se realiza y se imagina en un entretejido de prácticas y hábitos sociales y discursivos, en formas de higiene y resiliencia que configuran de un modo determinante no solo cómo entendemos el cuerpo, sino la manera en que se configura -o lo configuramos-, además de cómo lo representamos. La cuestión es, tal y como la he planteado más arriba, si dentro de la teoría feminista misma ese cuerpo femenino que se singulariza ha corrido mejor suerte.

Para empezar, y desde esa identificación entre mujer y cuerpo, sería comprensible que un cuestionamiento del concepto de mujer influyera en el lugar que va a encontrar el cuerpo dentro del feminismo. Aunque también va a depender de las reivindicaciones que hagan las mismas mujeres. Así un feminismo que contemple la igualdad tenderá a obviar un cuerpo que la ata a procesos biológicos que han servido para justificar una y otra vez su condición de sometimiento al y disponibilidad para el varón. El asunto es hasta qué punto la precariedad del cuerpo femenino dentro de la misma teoría feminista es consecuencia de la puesta en cuestión del concepto de mujer o si, por el contrario, no será más bien el rechazo a una realidad corporal concreta aquello que ha permitido y ayudado a desarmar el concepto de 'mujer' y 'mujeres' hasta el punto de considerarlo en nuestros días como innecesario para el mismo discurso del feminismo.

Si esto último fuera el caso, si efectivamente pudiera afirmarse que la deconstrucción de los conceptos 'mujer' y 'mujeres' está unida, o incluso provocada, por el cuestionamiento de un cuerpo femenino, esto mostraría no solo la prevalencia de esa 'confusión' entre cuerpo y mujer de la que ya he hablado, sino que implicaría además que las mismas mujeres han asumido, 
en buena medida, gran parte del discurso castrante respecto de su propio cuerpo.

Tensando algo más el argumento: esto significaría, por ende, que cierto afán por deshacerse de un cuerpo, o al menos por ignorarlo, pondría en evidencia hasta qué punto las mujeres habrían asumido aquello de que su anatomía es su destino (Freud) y buscan deshacerse de él a cualquier precio, aunque sea el de $s u$ realidad corporal. Y subrayo ese adjetivo posesivo porque ya sabemos hasta qué punto la experiencia corporal de todos, pero en particular la femenina, está mediada por el discurso. Recapitulo brevemente mi planteamiento: la cuestión central es ver si el desmontaje de los conceptos 'mujer' y 'mujeres' conllevó -o incluso requirió- un cuestionamiento radical y, a su vez, el desmontaje también de un cuerpo femenino -lo que a primera vista parece plausible, incluso necesario.

Un ejemplo clásico -y ciertamente radical- de esta postura es el de Simone de Beauvoir, quien plantea desde el principio con una gran claridad el carácter construido de la noción de 'mujer', pero al mismo tiempo retoma, sin cuestionarlos, buena parte de los prejuicios contra la corporalidad y sexualidad femenina. Y lo hace con un gesto de distancia extraordinario. Una distancia que puede muy bien ser atribuida a una mirada masculina del cuerpo femenino. Quien haya leído su libro El segundo sexo conoce pasajes en los que de Beauvoir describe el cuerpo femenino así como la relación de las mujeres con su cuerpo de una forma atroz, casi violenta y que contradicen, por otra parte, su idea de que la anatomía no debe constituir parte del destino de la mujer. De Beauvoir ve en el cuerpo femenino una fuente de malestar e incluso un impedimento para la realización de la mujer como un ser humano. Inmersa, como está de Beauvoir, en la dinámica existencialista, insiste desde las primeras páginas de El segundo sexo en la situación ambigua y contradictoria de las mujeres que como seres humanos se debaten, por una parte, entre el deseo de desarrollar su proyecto y su responsabilidad existencial y, por otra, en la sujeción a su condición femenina que, separada de la condición humana, la ha convertido en Otro, en una alteridad que parece tener un carácter irrevocable. Una condición, además, que si bien ella no considera natural, sino construida, la ha sometido "por su estructura fisiológica". Así afirma de Beauvoir cosas tales como: "La mujer tiene ovarios y un útero, y estas condiciones singulares la encierran en su subjetividad" (Beauvoir, 1987: 11-12). Y en otro lugar: "La joven [...] sufre su cuerpo como un tormento. [...] En gran parte, la angustia de ser mujer es lo que roe el cuerpo femenino" (Beauvoir, 1987: 75). Ante tales afirmaciones más duras aún con la corporalidad femenina en la segunda parte del texto, 
cuando de Beauvoir da cuenta de la experiencia vivida- una puede creer que la autora es víctima de esa tensión que según Nancy Cott está a la raíz de un feminismo que exige a las mujeres verse como individuos -por lo tanto, igual a los hombres- y a la vez como mujeres, lo que las sitúa socialmente en un lugar diferente (es decir, en el espacio de las mujeres) ${ }^{6}$. Esa tensión que coloca a las mujeres en un estado de disociación y conflicto continuos podría explicar el rechazo a un cuerpo sexuado que supone la sujeción a un lugar del que precisamente se quiere salir.

Linda Nicholson nos recuerda que, tras el final de la Segunda Guerra Mundial, muchas mujeres que habían tenido acceso a un trabajo profesional fuera de la esfera de lo doméstico desarrollaron una "identidad dual" en la que combinaban su papel de esposas y madres con la de seres autónomos (Nicholson, 2008: 165). Amén del peso de esta "sobrecarga de identidad" (Amoros, 2005: 299), el problema que se plantea aquí es el de la asimilación (¿inconsciente?) de unos valores masculinos que impregnan tanto la perspectiva como los propios valores con que las mujeres perciben $y$, por ende, juzgan la condición femenina. Este fenómeno no es nuevo y se refleja, por ejemplo, en una autora tan adelantada a su tiempo como Christine de Pizan, quien -a pesar de la acérrima defensa de las mujeres que hace en su La ciudad de las damas - no la crea para todas sino para aquellas damas "virtuosas", "dignas" y "valiosas" (de Pizan, 1995: 272). El asunto sería cuál es la medida de esa virtud y dignidad, bajo qué criterios se definen las conductas virtuosas y según se va avanzando en la lectura de La ciudad de damas no cabe duda de que las conductas que se dan como ejemplares remiten a valores muy masculinos. Notable es, sin embargo, que en lo que al cuerpo se refiere, de Pizan es una excepción, pues si bien es consciente de la vulnerabilidad del cuerpo femenino, también lo es de su fuerza. Lejos de todo prejuicio y descripción masculina de su época, de Pizan reivindica la propia experiencia corporal femenina como único criterio.

6 Nancy Cott, The Groundin of Modern Feminism, (citada por Nicholson, 2008: 155). En realidad, de Beauvoir era más que consciente de esa tensión como se desprende del capítulo que en El segundo sexo dedica a las mujeres independientes, allí afirma entre otras cosas: “... la mujer independiente se haya hoy dividida entre sus intereses profesionales y las preocupaciones de su vocación sexual. Le cuesta encontrar su equilibrio, y sólo lo asegura al precio de concesiones, sacrificios y acrobacias que le exigen una perpetua tensión" (Beauvoir, 1987: 485).

7 María-José Lemarchand, traductora y editora de la versión espańola de La ciudad de las damas, califica la defensa que hace de Pizan de la condición femenina precisamente desde su cuerpo, como una "revolución copernicana" en el contexto de la época (Lemarchand, 1995: 52-53). 
En el caso de otras autoras, sobre todo en aquellas que apuestan por un feminismo de la igualdad, esta transposición de valores del mundo masculino repercute indudablemente en la percepción -e incluso desvalorización- del cuerpo femenino. En su artículo "Woman as Body: Ancient and Contemporary Views", Elisabeth V. Spelman se hace eco de esta discriminación que sufre el cuerpo femenino por parte de autoras tan dispares como Simone de Beauvoir (El segundo sexo), Betty Friedan (The Feminine Mystique) o Shulamith Firestone (The Dialectic of Sex) (Spelman, 1982: 109-131). La tesis central de Spelman en ese artículo es que la infravaloración del cuerpo femenino que se desprende de la lectura de las autoras mencionadas podría entenderse como una aceptación acrítica de aquella clásica distinción entre mente y cuerpo (mind and body) que se da en la filosofía desde el comienzo y bajo cuya lógica binarista el cuerpo sería mucho menos importante que la mente (y el alma). Spelman recorre la obra de Platón para dar cuenta no solo del descrédito del cuerpo, sino y sobre todo cómo ese cuerpo -o mejor deberíamos decir corporalidad- está asociado, sin mayor mediación, a la mujer. De este modo esta "somatofobia" (somatophobia), como califica Spelman (Spelman, 1982: 119) a la denigración del cuerpo, se transfiere sin más a la mujer hasta el punto de quedar asociados los dos conceptos, como demuestra la historia de la filosofía.

Resulta quizá excesivo atribuir a autoras feministas como las citadas arriba, cuya obra tuvo tanta influencia en su momento, esa somatofobia de la que habla Spelman, aunque es innegable que tanto de Beauvoir como Firestone ven en la marcada corporalidad de la mujer un impedimento para su transcendencia o realización en tanto seres humanos, de modo que la liberación de las mujeres pasa irremediablemente por una superación de su corporalidad. Aunque no es este el lugar de profundizar en las similitudes y diferencias entre la obra de de Beauvoir y la de Firestone, sí es necesario señalar que hay una distinción básica en la apreciación que del cuerpo y la sexualidad femenina hacen estas dos autoras - no en vano median más de veinte ańos entre sus textos-. Mientras que de Beauvoir parece mirar con aversión, incluso con repugnancia, al cuerpo y sexualidad femeninos ${ }^{8}$, Firestone no cuestiona ni renuncia a la sexualidad femenina,

8 Puede leerse un ejemplo de lo que afirmo en Beauvoir, 1987: 131. Duele casi insistir en este punto, pero es difícil explicarse a veces de dónde le viene a de Beauvoir ese encono contra el cuerpo femenino. A menudo y por el tono y el grado de rechazo que delatan las palabras, se podría sospechar que tras la general "experiencia" de las mujeres, se transparenta la singularidad de la autora. Toril Moi, en su excelente "Psicografía" de Beauvoir titulada Simone de Beauvoir. The Making of an Intellectual Woman, comenta este gesto retórico de Beauvoir en el que combina un uso discreto del pronombre personal "yo" con una perspectiva desde la tercera 
muy al contrario, la reivindica. Para ella la "liberación de las mujeres de su biología" está centrada en la separación de la sexualidad femenina de su función reproductora y propone recurrir a la reproducción artificial. Al igual que otras teóricas del feminismo de la segunda ola, Firestone considera la superación de la heterosexualidad normativa o, más bien, la obligación de vivir la sexualidad solo en el marco de la heterosexualidad como otro punto que puede contribuir a la liberación de la mujer (Firestone, 1976: 258-259).

\section{Cuerpo diferente}

Cuestionar el marco de la heterosexualidad es sin duda una de las piedras de toque del feminismo de la segunda ola ${ }^{9}$, ese que reclama diferencias e identidades, que vuelve su mirada hacia el mundo y el actuar conjunto de las mujeres, y cuyos puntos de referencia ya no se agotan en la oposición masculino/femenino. En el "sistema de sexo/género"10 el cuerpo femenino es sobre todo un cuerpo lésbico que reniega de convertirse en cuerpo marcado por una forma de entender la biología femenina y de vivir un deseo que no provenga ni sea el de las propias mujeres. Como respuesta a un orden patriarcal que sitúa a las mujeres en una heterosexualidad obligatoria - para expresarlo con palabras de Adrienne Rich-, el lesbianismo se convierte en una forma de "resistencia", tal y como lo declaraba Cheryl Clarke en 1981, quien considera que "la lesbiana ha descolonizado su cuerpo" (2009: 149). En este mismo sentido se entiende la clásica y provocadora afirmación de Monique Wittig, datada en 1980, "las lesbianas no son mujeres" (Wittig, 2009: 143); y no lo son sencillamente porque ser 'mujer' solo es posible en el marco de una estructura heterosexual o bajo una forma particular de erotismo ${ }^{11}$.

persona cuando habla de la "mujer", pero subraya hasta qué punto la subjetividad de Beauvoir se esconde tras esa "mujer" generalizada. Lo que sí es sugerente es que eso se hace más notable cuando Beauvoir aborda la sexualidad femenina y las "taras de la femineidad" (Beauvoir, 1987:

25) que si bien no se justifican biológicamente, sí están ancladas en el cuerpo de las mujeres, en especial en su sexualidad.

9 Las siguientes palabras de Monique Wittig resumen muy bien parte de la crítica al modo de pensar heterosexual: “... el pensamiento heterosexual es incapaz de concebir una cultura, una sociedad, en la que la heterosexualidad no ordenara ni sólo todas las relaciones humanas, sino su producción de conceptos al mismo tiempo que todos los procesos que escapan a la conciencia" (Wittig, 2009: 139).

10 "As a preliminary definition, a 'sex/gender system' is the set of arrangements by which a society transforms biological sexuality into products of human activity, and in which these transformed sexual needs are satisfied" (Rubin, 1997: 28).

11 "The refusal to become (or to remain) heterosexual always meant to refuse to become a manor 
Así las cosas, el sistema de género/sexo sigue lidiando con una corporalidad adjetivada en términos de masculino o femenino, pero que articula un cuerpo que ahora se declina en claves de deseo y pretende escapar a cualquier forma de esquematismo o sujeción. El activismo lésbico va construyendo un cuerpo de afectos, empezando por la rabia que se predica desde algunos manifiestos hasta la recuperación de una forma diferente de la pasión y el erotismo que difundirán una Audre Lorde o la misma Luce Irigaray $^{12}$. Es un cuerpo femenino, liberado de toda función 'económica' de producción y reproducción, no se presenta desde coordenadas anatómicas ni biológicas, sino desde el deseo. No solo sexual y erótico, el deseo del que hablan los manifiestos y textos que promueven un activismo lésbico tiene que ver también con una revalorización de las mujeres que se perfilan de modo diferente una vez que se dejan atrás los marcos de referencia heterosexuales. Los varones ya no son la medida de todas las cosas; al contrario, lo son las mismas mujeres, su experiencia personal y las diferencias entre ellas mismas.

La pregunta que podría plantearse es hasta qué punto esa experiencia lésbica supondría un cambio en la percepción y en las experiencias del cuerpo femenino. En autoras como Audre Lorde y Luce Irigaray ese cambio conlleva de un modo claro una mirada positiva al cuerpo femenino y a una pérdida del miedo a la corporalidad. Sin embargo, los caminos teóricos que se han abierto posteriormente -cruzando a través de los discursos sobre la homosexualidad, el racismo y el colonialismo- exigen una mirada más atenta para entender la variedad de entretejidos discursivos y de identidades que surgen y que sin lugar a dudas afectan el cuerpo conceptual tal y como se entiende en esas perspectivas. Es indudable que la publicación de libros como El género en disputa o Cuerpos que importan de Judith Butler supusieron un giro copernicano, si no en las prácticas, sí en lo que a la articulación teórica se refiere. Aunque Butler no está sino recogiendo y reelaborando discursos anteriores, la reconceptualización que hace en esos textos del sistema sexo/ género o el cuestionamiento de un sujeto feminista identificado sin más con las mujeres -así como la crítica a las políticas identitarias- pueden servir de

a woman, consciously or not. For a lesbian this goes further tan the refusal of the role 'woman'. It is the refusal of the economic, ideological, and political power of a man" (Wittig, 1997: 265).

12 Cf. Radical lesbians, "The Woman-Identified Woman": "What is a lesbian? A lesbian is the range of all women condensed to the point of explosion" (Nicholson, 1997: 153). Hay una versión española de este texto, "La mujer identificada con mujeres" (1970). Allí la cita dice así: "Una lesbiana es la rabia de todas las mujeres condensada y a punto de estallar" (Mérida Jiménez, 2009: 75). 
ejemplo para entender la repercusión que la aparición de esos textos tuvo en su día.

\section{Cuerpos queer}

Sea como sea, al margen del momento y contexto 'conceptual' que escojamos, la imagen de agencia de la corporalidad lésbica contrasta sin duda con la pasividad atribuida al cuerpo femenino heterosexual. Más que de pasividad, empero, se trataría de una entrega, un 'estar a disposición de' que se manifestaría más claramente en un cuerpo heterosexuado. Ese cuerpo heterosexuado sería más susceptible a los discursos -Foucault lo analizó con exhaustividad- y estaría atrapado en un círculo de significados y significantes. La agencia de un cuerpo lésbico u homosexuado, por el contrario, radicaría en la resistencia a situarse en un espacio normativo cuyos límites pueden ser desplazados interviniendo precisamente con y en ese círculo de significados y significantes que encuentran en los cuerpos su campo de juego, pero también de batalla. Al menos eso es lo que podría parecer a primera vista desde una corporalidad lésbica. Y, sin embargo, el cuerpo lésbico no es en nada ajeno a aquellos espacios acotados por la matriz heterosexual que están obligados a recorrer de todos modos, aún sin querer. A recorrer convirtiendo los movimientos de inclusión y exclusión en un complicado engranaje de paraísos e infiernos, perfomances y diversiones miméticas del que las teorías queer se han hecho eco. Debido a eso, el nuevo cuerpo que perfila un feminismo queer es uno que voluntariamente o por obligación se mueve -y sufre también- entre los hilos sueltos de la madeja de relaciones que dibujan el patrón y normas heterosociales que impera en la mayoría de las sociedades ${ }^{13}$.

En el último capítulo de El género en disputa, y en diálogo con el trabajo de Monique Wittig sobre el lesbianismo, Butler señala la ingenuidad de profesar una suerte de "purificación de la homosexualidad" que consistiría en creer que la homosexualidad y el lesbianismo estarían no solo " ...'fuera' de la matriz heterosexual" sino que además ni siquiera estarían supeditados a "las reglas heterosexuales". En realidad -y siguiendo la argumentación de Butler-, el potencial subversivo así como la capacidad resignificadora procedente de las posturas homosexuales solo podrían desarrollarse desde la

13 A este respecto es recomendable la lectura de un breve manifiesto anónimo titulado "Queers Read This: I Hate Straights" y publicado en español bajo el título: "Maricas, leed esto: odio a los heteros" (1990) (Mérida Jiménez, 2009: 231-246). 
estructura normativa heterosexual (Butler, 2007: 241). Más aún, es gracias a las constantes referencias a esa matriz heterosexual que la "heterosexualidad idealizada" termina por manifestarse como un "ideal regulador" que ayudaría a la "construcción de la coherencia [que] encubre las discontinuidades de género que están presentes en el contex to heterosexual, bisexual, gay y lésbico, en el que el género no es obligatoriamente consecuencia directa del sexo y el deseo, o la sexualidad en general, no parece ser la consecuencia directa del género; en realidad, donde ninguna de estas dimensiones de corporalidad significativa se manifiestan o reflejan una a otra" (Butler, 2007: 265-266). Esa 'coherencia' al servicio de la heterosexualidad se consigue y mantiene gracias a una puesta en escena teatral, en la que el cuerpo es el escenario de "actos, gestos y deseos" que no solo imitan una identidad sino que la inventan una y otra vez, haciéndola real a fuerza de repetición (Butler, 2007: 266). Se completa así, en el esquema butleriano, un círculo de regulación y normalización en el que actor y personaje terminan siendo inseparables, más aún indistinguibles. Es esta relación teatral - "una reiteración estilizada de actos"14 - la que por ende construye mediante la "estilización del cuerpo" una identidad producto asimismo de "un efecto del género" (Butler, 2007: 273). Despojada de todo marco ontológico, la identidad se convierte en materia semiótica en la que la interpretación -prácticamente en todas las acepciones del término: sentido de actuación, de ejecución legal, de representación y traducción- es el fundamento si no de su ser, sí de su significado ${ }^{15}$.

El cuerpo pasivo y vulnerable de las mujeres -ese que en la dialéctica del patriarcado estaba naturalizado por entero y sometido al deseo y a la necesidad de reproducción masculinos- ahora no es débil pero sí inestable; no está sometido al deseo, sino que es producto de él; tampoco está ya necesariamente sujeto a una heterosexualidad obligada por la reproducción,

14 Subrayado en el original.

15 Butler no estaría de acuerdo con esta lectura por considerar que en esa 'interpretación' se sobreentiende una intencionalidad ("voluntad o la elección”) del sujeto que actúa. Insiste en que esa actuación "sirve para ocultar, si no ya para renegar de aquello que permanece siendo opaco, inconsciente, irrepresentable". De ahí que considere "un error reducir la performatividad a la manifestación o actuación del género” (Butler, 2002: 328-329). La cuestión es complicada porque esta afirmación de Butler podría entenderse como si su concepto de performatividad apelara a más dimensiones que la "superficie" corporal (Butler, 2007: 266), reproduciendo una dialéctica del afuera y el adentro, de lo visible y lo invisible, de lo aparente y real que no encuadraría bien con su teoría del género. Tampoco estaría claro cuál sería el estatuto de un cuerpo que es superficie y base de una representación o efecto del género y, al mismo tiempo, resultado -es decir, la representación misma tanto de sí, como de ese género al que por otro lado ofrece un lugar de visibilidad. 
pero sí está atado como nunca a hormonas, glándulas, órganos y fluidos corporales. Este cuerpo histriónico que se divierte subvirtiendo la norma y, al mismo tiempo, padece con angustia su coerción tiene algo de trágico, casi desesperado. Es como si tras el juego semiótico hubiera un afán de ser, o al menos el sueño de que detrás de ese cuerpo hubiera un alma. Sea como sea, lo que me interesa señalar es el lugar tan distinto que ocupa el cuerpo en los nuevos discursos posfeministas. El 'pos' que antepongo no tiene un carácter temporal, sino más bien espacial, pues se trata de un feminismo que está en otro lugar, el cuerpo como lugar en el que además se articula dicho feminismo. En efecto, si concedemos, tal y como hemos visto, que la identidad del género es una conquista performativa que se gana en y a través del cuerpo, es indudable que ese cuerpo pase a formar parte central del discurso de ese otro feminismo, denominado queer. Pongo énfasis en el 'otro' por dos razones: primero, porque el uso lingüístico del término inglés queer como insulto y recriminación marcaba, al parecer, esa exclusión de los homosexuales que terminó por convertirse en cohesión para esos grupos y, por ende, en su signo de otredad (Butler, 2002: 318); segundo, porque la inclusión de ese término en la teoría feminista también ha derivado en formas diferentes de entender tanto los discursos como el quehacer del feminismo ${ }^{16}$.

No es fácil rastrear lo que en el camino queer hay de común con la teoría feminista el estar muy unido al activismo político y de reivindicaciones sociales y cuya acción está cada vez más institucionalizada ${ }^{17}$. Lo que sí parece fuera de toda duda es que el cuerpo queer no solo no termina con los binarismos de fuertes reminiscencias biológicas propias del patriarcado, sino que además los retoma haciendo de ellos armas de crítica contra la misma teoría feminista. Quizá está tensión se explique desde una teoría de la performatividad en su versión butleriana, para la que "el término queer emerge como una interpelación que plantea la cuestión del lugar que ocupan la fuerza y la oposición, la estabilidad y la variabilidad dentro de la performatividad" (Butler, 2002: 318), pero no termina de convencer en el estilo beligerante de una autora como Beatriz/Paul Preciado. Y no tanto por

16 Fue la teórica feminista italiana Teresa de Lauretis quien en 1991 introdujo ese término en la teoría feminista en un número especial de la revista Differences (White, 2007: 1), si bien pocos años después -y debido el giro institucional y comercial que estaba tomado este término- ella misma renunció a usarlo. Este es un tema que requiere más atención de la que le puedo dar aquí.

17 Mientras trabajo en este texto, se publica la noticia de que la Casa Blanca en Washington ha contratado a la primera funcionaria transexual Raffi Freedman-Gurspan. 
la beligerancia en sí, sino por el tipo de lenguaje que la acompaña.

Desde sus primeras publicaciones, Preciado - siguiendo el gesto queersitúa el cuerpo como lugar de reflexión teórica y activismo político al mismo tiempo. Un cuerpo que adquiere protagonismo como cruce de caminos biológicos y tecnológicos, pero también como lugar de prácticas sexuales transgresoras que no solo estarían afuera de aquella heterosexualidad normativa que ya veíamos criticada en el feminismo de la segunda ola, sino también de la misma homosexualidad.

El "cuerpo-ciborg" que propone Preciado en su Manifiesto contrasexual. Prácticas subversivas de identidad sexual se caracteriza por ser de una biología y domesticidad incontrolables al mismo tiempo que área de prácticas y tecnologías sexuales de distinta índole. Así la contra-sexualidad se define como "una teoría del cuerpo que se sitúa fuera de las oposiciones hombre/mujer, masculino/femenino, heterosexualidad/homosexualidad" y cuya sexualidad no es otra cosa que tecnología (Preciado, 2002: 19). Su tarea se centra en "el estudio de los instrumentos y los aparatos sexuales $y$, por lo tanto, las relaciones de sexo y género que se establecen entre el cuerpo y la máquina", así como en "la comprensión del sexo del género como cibertecnologías complejas del cuerpo" (Preciado, 2002: 21, 33). La maquinaria corporal que despliega Preciado a lo largo de este manifiesto da como resultado "unos cuerpos parlantes" que ella designa como “ 'postcuerpos' o wittigs" (Preciado, 2002: 36) que habitarían un mundo regido por esa contrasexualidad. Hasta aquí podría aplaudirse la ironía de Preciado, incluso otorgarle cierta originalidad, si no fuera porque algo en su manifiesto recuerda al de Firestone.

Lo que no deja de sorprender son los ejes en torno a los que se conforma una sociedad organizada en la ideología contrasexual. Esos ejes son el dildo y el ano, órga no muy biológico, por lo demás. El ano se nos presenta en la versión de Preciado como un órgano de placer ciertamente democrático y universal, cuyo potencial revolucionario radica, por una parte, en que es "una zona de pasividad primordial" (¡!), mientras que, por otra, en constituirse como "un espacio tecnológico" (Preciado, 2002: 27). El dildo es el exponente máximo de la tecnología y, si bien es imitación y su sustituto, no deja de ser al mismo tiempo "origen del pene" (Preciado, 2002: 20, 25). Es también parte de la "lógica de la heterosexualidad" y a la vez "instrumento entre otras máquinas orgánicas e inorgánicas (las manos, los látigos, los penes, los cinturones de castidad, los condones, las lenguas, etc.) y no simplemente como la réplica de un miembro único" (Preciado, 2002: 64). Como se sigue de esa cita, un 
dildo en la extrema locuacidad de Preciado es prácticamente todo, y termina casi con todo, incluidos el falo y su valor simbólico (Preciado, 2002: 63). Es un passepartout sobre cuya base Preciado desarrolla una dialéctica asimismo 'díldica' y tan postiza como el dildo mismo, que opera haciendo gala de un lenguaje muy sexista y machista. El lugar que ocupa el ano dentro de esa dialéctica-¿̨o debería escribir dildiléctica?- no deja muchas dudas acerca de esa actitud sexista: "La recuperación del ano, como centro contra-sexual del placer, tiene puntos comunes con la lógica del dildo: cada lugar del cuerpo no es solamente un plano potencial donde el dildo puede trasladarse, sino también un orificio-entrada, un punto de fuga, un centro de descarga, un eje virtual de acción-pasión" (Preciado, 2002: 28). He aquí la gran fantasía -ya tan trillada por la masculinidad- de Beatriz/Paul Preciado: un órganotecno con una potencia y erección garantizadas y un cuerpo-ano siempre abierto, siempre pasivo, siempre dispuesto a ser penetrado. Lo irritante de este discurso es que además se nos presente como una salida a los binarismos que provienen de la heterosexualidad normativa, y lo que en realidad se propone en ese manifiesto reproduce - de una manera irreverente, eso sídialécticas ya conocidas, que el feminismo anterior empezaba a considerar si no superadas, al menos sí declaradas como reprobables.

Todas las dudas acerca de la actitud machista de Preciado se despejan tras la publicación de su libro, de carácter confesional, Testo Yonqui (Preciado, 2008). Y no tanto porque en él narre su experiencia con la testosterona que ella se va suministrando con regularidad durante un tiempo. Las peores visiones que Preciado despertaba con su manifiesto se explicitan y describen con bastante detalle. Dichas visiones sonrojan a las feministas 'puritanas', pero no de vergüenza, sino de indignación ante un sexismo y machismo de marcado carácter violento y prepotente que feminiza lo que desprecia y desprecia lo femenino. No creo necesario justificar lo que digo con ninguna cita, hacerlo sería reproducir parte de esa violencia. Si hago referencia a este texto es, primero, por el protagonismo que sigue teniendo el cuerpo en todo su discurso y, segundo, porque despliega una retórica queer que pretende ser rompedora y revolucionaria, cuando en realidad reproduce sin ningún pudor las viejas oposiciones patriarcales con las que se supone quiere terminar. Más aún las vuelve a poner en circulación envueltas y adornadas en un lenguaje con visos progresistas jugando con la provocación y la desmesura. ¿Cómo entender que a estas alturas se esté hablando de los biohombres y las biomujeres? (Preciado, 2008: 107). Preciado insiste en la destrucción de los binarismos masculino/femenino o hetero/homosexualidad. Sin embargo, se presentan cuerpos marcadamente sexuados y cuyos juegos transgresores 
siguen teniendo lugar $-\mathrm{y}$ sentido- desde las coordenadas de masculino y femenino. Las nuevas 'identidades' de género siguen nutriéndose de estas oposiciones y marcando diferencias y distancias asimismo jerarquizadas. Más que de identidades deberíamos hablar de corporalidades, pues son cuerpos susceptibles de ser manipulados y transformados gracias a la técnica y a los productos farmacéuticos (hormonas, por ejemplo) y que además ofrecen espacios y contenedores de emociones y afectos. El cuerpo que se nos presenta en Testo Yonqui es desbordante y desbordado, es un "sujetocuerpo" y "un sistema tecno-vivo"; es "el cuerpo de la multitud" pero sobre todo es "político" y no solo porque está en continuo contacto con otros cuerpos, sino porque puede convertirse en "uno de los conectores somáticos a través de los cuales circula el poder, el deseo, la libertad, la sumisión, el capital, la basura y la rebelión" (Preciado, 2008: 108, 246). Este multicuerpo es el que va a dar paso a un nuevo feminismo de redes, lazos, cohabitaciones y prácticas corporales sin más sujeto ni centro que el de las relaciones que se producen entre esos cuerpos. Ese movimiento feminista corresponde a "la modernidad pornopunk" que entiende lo queer "como un momento crítico en un proceso más amplio de producción de subjetividades disidentes dentro del régimen farmacopornográfico" (Preciado, 2008: 240-246).

\section{Conclusiones}

El nuevo feminismo post-queer que predica Preciado ha retomado ese cuerpo indeterminado que el feminismo clásico desechó por considerarlo fuente y justificación de la discriminación de las mujeres para sobredeterminarlo y multiplicarlo. Quizá por eso estas nuevas formas de disidencia queer tengan más sex-appeal, pero desde luego también más de esa biología que hacía estremecerse a la vieja guardia feminista. Al cuerpo de sangre, flujos y músculos se añade uno manipulable sobre la base de hormonas y fármaco-tecnología. El cuerpo vuelve en plural, los cuerpos, con una fuerza rabiosa y un exhibicionismo desbocado.

Habría que aclarar por qué estas teorías tendrían que seguir siendo consideradas feministas cuando rechazan expresamente que dicho movimiento se asocie con las mujeres, sobre todo con lo que las queer denominan biomujeres. Las mujeres no son ya ni su sujeto ni tampoco su tema. ¿Por qué seguir insistiendo en llamar feminista a un movimiento que discrimina a las mujeres desde una postura de nuevo tan sexista? 


\section{Referencias bibliográficas}

Amorós Celia (2005), Las grandes diferencias y sus pequeñas consecuencias... para las luchas de las mujeres, Cátedra, Madrid.

Beauvoir Simone de (1987), El segundo sexo, 2.vol., Ediciones Siglo XXI, Buenos Aires.

Butler Judith (2004), Undoing Gender, Routledge, New York/London.

(2007), El género en disputa. El feminismo y la subversión de la identidad, Editorial Paidós, Barcelona [(1990; 1999), Gender Trouble. Feminism and the Subversion of Identity, Routledge, New York].

(2002), Cuerpos que importan: sobre los limites materiales y

discursos del 'sexo', Editorial Paidós, Buenos Aires [(1993) Bodies that Matter. On the Discursive Limits of "Sex", Routledge, New York].

Clarke Cheryl (2009), "Lesbianismo: un acto de Resistencia (1980)", en: Mérida Jiménez, Rafael M.(ed.), Manifiestos gays, lesbianos y queer. Testimonios de una lucha (1969-1994), 149-163, Icaria, Barcelona.

Eagleton Terry (1990), The Ideology of Aesthetic, Blackwell Publishers, Oxford [(2006), La estética como ideología, Trotta Editorial, Barcelona).

Foucault Michel (2010), El cuerpo utópico. Las heterotopias, Ediciones Nueva Visión SAIC, Buenos Aires.

Honegger Claudia (1991), Die Ordnung der Geschlechter. Die Wissenschaften vom Menschen und das Weib 1750-1850 (El orden de los géneros. Las ciencias humanas y la hembra 1750-1850), Campus Verlag, Frankfurt am Main.

Lyotard Jean François (1988), La diferencia, Editorial Gedisa, Barcelona. 
Peña Aguado María Isabel (2015), "El feminismo y sus caballos de Troya", Filósofas en con-texto, Editorial Puntángeles, Valparaíso (en prensa).

Pizan Christine de (1995), La ciudad de las damas, traducción y edición de María-José Lemarchand, Siruela, Madrid.

Preciado Beatriz (2002), Manifiesto contra-sexual. Prácticas subversivas de identidad sexual, Editorial Opera Prima, Madrid.

(2008), Testo Yonqui, Espasa Calpe, Madrid.

Radicalesbians (1997), “The Woman-Identified Woman”, Nicholson, Linda (ed.), The Second Wave. A Reader in Feminist Theory, 153-157, Routledge, Oxford. Hay una versión española de este texto: (2009), "La mujer identificada con mujeres (1970)", Mérida Jiménez, Rafael M. (ed.), Manifiestos gays, lesbianos y queer. Testimonios de una lucha (1969-1994), 75-82, Icaria, Barcelona.

Rubin Gayle (1997), “The Trafic in Women. Notes on the 'Political Economy' of Sex", Nicholson, Linda (ed.), The Second Wave. A Reader in Feminist Theory, 27-62, Routledge, Oxford.

Sarasin Philipp (2011), Reizbare Maschinen. Eine Geschichte des Körpers 1765-1914, Suhrkamp, Frankfurt.

Schmid Pia (1995), "Sauber und schwach, stark und stillend. Der weibliche Körper im pädagogischen Diskurs der beginnenden Moderne”, Fahrideh Akashe-Böhme, Von der Auffälligkeit des Leibes, Suhrkamp, Frankfurt a.M.

Spelman Elisabeth V. (1982), "Woman as Body: Ancient and Contemporary Views”, Feminist Studies, vol. 8, No.1, 109-131.

Wittig Monique (1997), “One is Not Born a Woman”, Nicholson, Linda (ed.), The Second Wave. A Reader in Feminist Theory, 265-271, Routledge, Oxford.

Wittig Monique (2009), “El pensamiento heterosexual (1978-1980)”, Mérida Jiménez, Rafael M. (ed.), Manifiestos gays, lesbianos y queer. Testimonios de una lucha (1969-1994), 133-143, Icaria, Barcelona. 